\section{POS0783 LUPUS NEPHRITIS: HISTOLOGICAL FEATURES AND LONG TERM OUTCOMES IN A LARGE SINGLE- CENTRE COHORT}

A. I. Celia ${ }^{1}$, F. R. Spinelli ${ }^{1}$, C. Garufi ${ }^{1}$, S. Truglia ${ }^{1}$, V. A. Pacucci ${ }^{1}$, F. Ceccarelli ${ }^{1}$, C. Pirone ${ }^{1}$, F. Natalucci ${ }^{1}$, M. Speziali ${ }^{1}$, C. Alessandri ${ }^{1}$, F. Conti ${ }^{1} .{ }^{1}$ Department of Clinical Internal, Anaesthesiological and Cardiovascular Sciences, Sapienza University, Rome, Italy

Background: In Systemic Lupus Erythematosus (SLE) patients the incidence of lupus nephritis $(\mathrm{LN})$ is about $40 \%{ }^{(1)}$. The rate of progression to end stage renal disease (ESRD) is $4.3-10.1 \%^{(2)}$ and renal involvement is a strong predictor of morbidity and mortality.

Objectives: To describe clinical, histological features and renal outcomes of LN patients included in our single-center registry reporting data from more than 30 years. Moreover, we examined the correlation between clinical features at LN diagnosis and therapeutic lines used during the course of a 24 years follow-up. Methods: A total of 71 patients were diagnosed with LN from 1989 to 2020. Demographic features and laboratory abnormalities (serum creatinine, 24 hours urine protein, urinary sediment, ds-DNA) at the time of LN diagnosis and at last available follow-up, were evaluated. We also examined renal biopsy performed and the histological classes (proliferative vs non-proliferative). We considered the increase number of therapeutic lines adopted as a negative prognostic factor in response to therapy. Mean (SD) or median (IQR) were used according the variable distribution. T-test and Chi square and Mann-Whitney were used and $p$-value $<0.05$ were considered significant. Results: Among 71 patients with LN, 63 (88.7\%) were females and 8 (11.3\%) males, with a F/M ratio of 6 . Median SLE duration was 180 (162) months. The median age at the onset of nephritis was 28 (19.5) years and occurred in median after 12 (60) months from SLE diagnosis.

Sixty patients underwent a biopsy: the histology showed class III or IV prolipherative glomerulonephritis in 49 patients $(81.6 \%)$ and a non-proliferative class in $11(18.3 \%)(p<0.0001)$. Median serum creatinine value, 24 hours urine protein, urinary sediment, anti-ds-DNA at $L N$ onset are reported in Table 1. Induction therapy was performed with cyclofosfamide in $14.5 \%$ of cases, mycophenolate in $21.1 \%$, rituximab in $1.3 \%$, cyclosporine $A$ in $1.9 \%$ and azathioprine in $4.6 \%$. The lines of therapies adopted during the follow-up ranged between a minimum of 0 and a maximum of 6 lines with a median value of 1 .

Overall, the median follow-up was 180 (111) months and 30 (21.3\%) patients had at least 120 months of follow-up. Median serum creatinine value, 24 hours urine protein, urinary sediment and eGFR last available follow-up are reported in Table 1. Three patients underwent dialysis and 3 kidney transplantation.

Eight patients underwent a re-biopsy: $7(87.5 \%)$ had a proliferative class and 1 $(12.5 \%)$ had a membranous class $(\mathrm{p}=0.01)$. Median serum creatinine value, 24 hours urine protein, urinary sediment at re-biopsy are reported in Table 1. In re-bioptized subgroup patients, induction therapies were cyclofosfamide in $50 \%$ of cases, mycophenolate in $12.5 \%$, cyclosporine A in $25 \%$ and azathioprine in $12.5 \%$. There were not statistically significant differences among the age on LN onset, the time from renal onset to the onset of the disease and the number of therapeutic lines adopted (Figure 1).

Conclusion: Among patients with $\mathrm{LN}$ the proliferative classes are the most common. At the 15 -year follow-up 2,1\% had renal transplantation and 2,1\% dyalisis. We did not detect any association between age at diagnosis, time from renal impairment and the number of therapeutic lines.

REFERENCES:

[1] Fanouriakis A et al. Update EULAR/ERA-EDTA recommendations for the management of lupus nephritis. Ann Rheum Dis 2019.

[2] Hanly JG et al. The frequency and outcome of lupus nephritis: results from an international inception cohort study. Rheumatology 2016.

Table 1. Laboratory features in SLE patients at LN onset, at last available follow-up and in re-bioptized patients.

\begin{tabular}{|c|c|c|c|c|}
\hline & $\begin{array}{l}\text { LN onset } \\
\text { (n 71) }\end{array}$ & $\begin{array}{l}\text { AFTER } 10 \\
\text { years long } \\
\text { FOLLOW-UP } \\
\text { (n 30) }\end{array}$ & $P$ value & $\begin{array}{l}\text { Re-bioptized } \\
\text { patients } \\
\text { (n 8) }\end{array}$ \\
\hline $\begin{array}{l}\text { Serum creatinine }(\mathrm{mg} / \mathrm{dl}) \\
24 \text { hours urine protein } \\
(\mathrm{mg} / 24 \mathrm{~h})\end{array}$ & $\begin{array}{l}0.81(+/-0.4) \\
3000(+/-3707)\end{array}$ & $\begin{array}{l}0.87(+/-0.60) \\
330(+/-793)\end{array}$ & $\begin{array}{l}0,07 \\
<0,00001\end{array}$ & $\begin{array}{l}1.05(0.45) \\
5068(2392)\end{array}$ \\
\hline Active urinary sediment & $\begin{array}{l}64 \text { patients } \\
(45,44 \%)\end{array}$ & $\begin{array}{l}2 \text { patients } \\
(6.66 \%)\end{array}$ & $<0,00001$ & 8 patients $(100 \%)$ \\
\hline $\begin{array}{l}\text { Anti-ds-DNA + } \\
\text { eGFR }<50 \mathrm{ml} / \mathrm{h}\end{array}$ & 30 patients & 12 patients $(3.6 \%$ & & \\
\hline
\end{tabular}

Disclosure of Interests: None declared

DOI: 10.1136/annrheumdis-2021-eular.3710

\section{POS0784 \\ AUDIOLOGIC EVALUATION IN SYSTEMIC LUPUS ERYTHEMATOSUS PATIENTS AND IMPACT OF HYDROXYCHLOROQUINE THERAPY}

S. Tharwat ${ }^{1}$, W. Elshawaf ${ }^{2}$, M. K. Nassar ${ }^{3} .{ }^{1}$ Mansoura University, Internal Medicine, Rheumatology \& Immunology, Mansoura, Egypt; ${ }^{2}$ Mansoura University, Audiology Unit, ORL Department, Mansoura, Egypt; ${ }^{3}$ Mansoura
University, Mansoura University Nephrology and Dialysis Unit, Internal Medicine Department, Mansoura, Egypt

Background: Hydroxychloroquine (HCQ) is a commonly used agent in the treatment of rheumatic diseases including systemic lupus erythematosus (SLE). [1] Objectives: The aim of this study was to evaluate the hearing function in SLE patients and assess the impact of chronic $\mathrm{HCQ}$.

Methods: This study was carried out on 60 individuals (48 SLE and 12 healthy controls). The SLE patients were divided into HCQ group $(n=36)$ and non-HCQ group ( $n=12$ ) according to the chronic administration of HCQ. All participants were assessed by full audiological history and extended high frequency audiometry at frequencies $9,10,11,2,12.5,14,16,18$ and $20 \mathrm{KHz}$.

Results: When comparing the study SLE patients with healthy controls,there was a statistically significant difference regarding patient reported otological manifestations such as tinnitus $(p=.021)$, vertigo $(p=.002)$ and hearing impairment $(p=.042)$ while there was no significant difference regarding deafness or ear buzzing in one or both ears. $\mathrm{HCQ}$ group showed more hearing impairment at frequency 9000 and $20000 \mathrm{~Hz}$ than non-HCQ group ( $\mathrm{p}=.004,<.001$ respectively). Conclusion: Otological symptoms and sensorineural hearing loss are prevalent among SLE patients. Chronic administration of HCQ may have an ototoxic effect. REFERENCES:

[1] Fiehn, C., et al. "Safety management in treatment with antimalarials in rheumatology. Interdisciplinary recommendations on the basis of a systematic literature review." Zeitschrift für Rheumatologie (2020): 1-9.

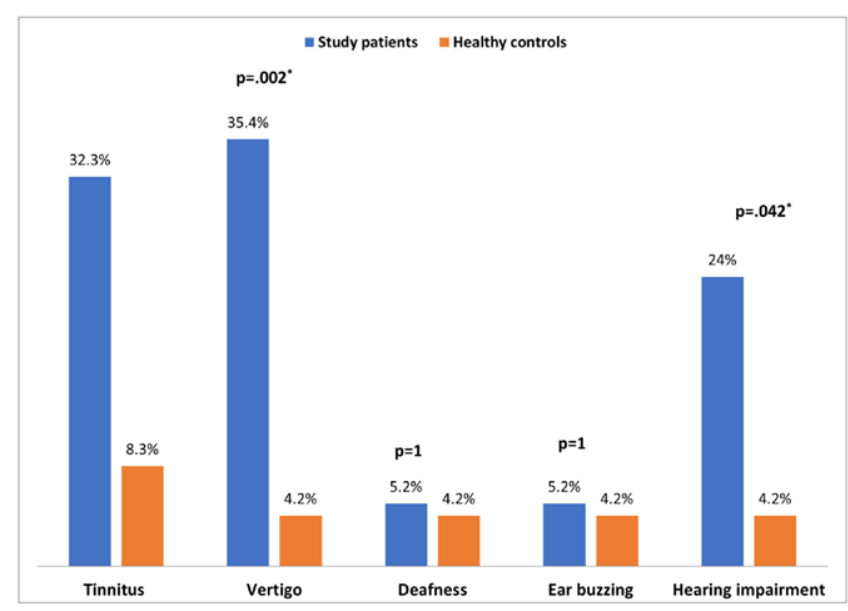

Figure 1. Otological manifestations in the study SLE patients $(n=48)$ and the healthy controls $(n=12)$

Disclosure of Interests: None declared

DOI: 10.1136/annrheumdis-2021-eular.3742

\section{POS0785 CHANGING EXPRESSION PROFILES OF LONG NONCODING RNAS, MIRNAS, MRNAS AND CIRCULAR RNAS IN LABIAL SALIVARY GLANDS OF PRIMARY SJÖGREN'S SYNDROME (PSS)}

G. Feng ${ }^{1}$, L. Huang ${ }^{2}$, J. Ji ${ }^{3}$, C. Dong ${ }^{3}$, Y. $\mathrm{Xia}^{3}$, C. Cheng ${ }^{4}$, Z. Gu ${ }^{3} .{ }^{1}$ Affiliated Hospital of Nantong University, Department of Stomatology, Nantong, China; ${ }^{2}$ Affiliated Hospital of Nantong University, Department of Critical Care Medicine, Nantong, China; ${ }^{3}$ Affiliated Hospital of Nantong University, Department of Rheumatology, Nantong, China; ${ }^{4}$ Nantong University, Jiangsu Province Key Laboratory for Inflammation and Molecular Drug Target, Nantong, China

Background: Primary Sjögren's syndrome (pSS) is a relatively common autoimmune disease characterized by oral and ocular dryness. An increasing number of studies have revealed that long non-coding RNA (IncRNA), miRNA, mRNA and circular RNA (circRNA) contributes to the pathogenesis of autoimmune diseases. Objectives: To explore IncRNA, miRNA, mRNA and circRNA expression profiles in labial salivary glands (LSGs) in pSS patients and their biological functions in the regulation of pSS.

Methods: The expression of 75,550 IncRNAs, 2,318 miRNA, 20,292 mRNAs and 6,877 circRNAs were determined in the LSG of six pSS patients and six healthy controls using microarray experiments. Validation was performed in pSS patients and controls using real-time PCR. LncRNA-mRNA co-expression and gene-pathway networks were constructed using bioinformatics software.

Results: A total of 599 IncRNAs (upregulated: 279, downregulated: 320), 78 miRNAs (upregulated: 26, downregulated: 52), 615 mRNAs (upregulated: 590, downregulated: 25) and 160 mRNAs (upregulated: 110, downregulated: 50) were differentially expressed in the LSGs of $p S S$ patients. Five of these IncRNAs were validated using real-time PCR. IncRNA HCP5, IncRNA SNHG5, IncRNA IFI44L, IncRNA CMPK2 were significantly upregulated and IncRNA TTYH1 were downregulated in pSS. GO 